\title{
Copied citations give impact factors a boost
}

Tom Clarke

Scientific papers that are not widely read and that lack any great influence can end up being classed as high-impact, claim researchers in California.

The mistake occurs because citations are often just copied from the reference list of one paper to another. A largely unremarkable or unread paper can therefore end up becoming highly cited, the researchers suggest.

"Simple mathematical probability, not genius, can explain why some papers are cited a lot more than others," says Vwani Roychowdhury, an electrical engineer at the University of California, Los Angeles.

The assertion hinges on a previous analysis by Roychowdhury and his colleague Mikhail Simkin. Last year, they tracked identical errors in reference lists citing a seminal 1973 paper and concluded that almost $80 \%$ of authors had not read the paper in question before citing it (see Nature 420, 594; 2002).

The pair have now built on that finding to generate a mathematical model to predict citation levels. They tested their prediction in an analysis of about 24,000 articles from the journal Physical Review D stored on

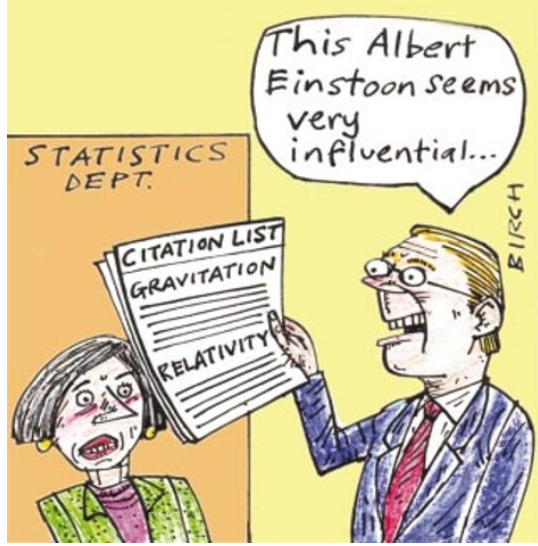

SPIRES, a database of high-energy physics papers. The database sorts papers into six categories according to the number of citations that they receive - those receiving 500 or more are classed as 'renowned'.

Roychowdhury and Simkin's model closely matched the real distribution of citations. In results posted on the arXiv preprint server, they predicted that 40 papers would be cited 500 times or more. In reality, 44 articles in Physical Review D are renowned.

"If people cite randomly, the citation distribution would be the same as in reality," says Roychowdhury. Given that citation patterns are similar in other sciences besides physics, the outcome of the model should be similar for biology or engineering papers, he argues.

The idea is "fascinating, unorthodox and inspiring", says bibliometrics expert Anthony van Raan of Leiden University in the Netherlands. But although van Raan's research also suggests that copying is rife, he believes that citations levels generally reflect a paper's true impact. Researchers tend to copy references rationally, rather than randomly, and do so from papers that they have read, he says.

Ben Martin, director of the Science Policy Research Unit at the University of Sussex in Brighton, UK, points out that the new model is important, even if it only partially reflects reality. "Citations are a surrogate for quality," he says. "Some departments look at these when making decisions in recruitment or tenure. Even if this is just a quirk, it's one that is worth airing."

http://xxx.lanl.gov/abs/cond-mat/0305150

\section{Researchers divided over ethics of a ban on cloning}

\section{Alison Abbott, Berlin}

The German government last week began a push for an international ban on all types of human cloning.

But at meeting to discuss the issue held in Berlin and sponsored by the German science ministry - some researchers claimed that even in the usually clear-cut case of reproductive cloning, current ethical arguments in favour of a ban are far too simplistic.

The meeting was scheduled after the country's parliament voted last month to ask the United Nations to call for an international ban on both therapeutic and reproductive cloning, practices already illegal in Germany.

The ethics of therapeutic cloning, in which stem cells are produced for research purposes, are most controversial — some countries, such as Britain and China, allow the practice, whereas others, such as Italy, do not. Suggestions for bans on reproductive cloning usually attract unanimous support, with ethicists arguing that few cloned embryos result in live births, and that surviving clones are usually abnormal or sick.

But Eckhard Wolf of the University of Munich, an expert on the cloning of farm animals, is one of several at the Berlin meeting who predicted that these safety issues will eventually be resolved. He argued that the ethical objections to a ban will then become much more difficult to resolve.

The suggestion is controversial. Other researchers present, including Rudolf Jaenisch, a geneticist at the Whitehead Institute for Biomedical Research in Cambridge, Massachusetts, asserted that some problems with cloned embryos, such as faulty gene regulation, are intrinsic to the process.

But ethicists note that if safety is taken out of the equation, other arguments against reproductive cloning - such as the psychological pressure that clones may find themselves under because their 'twin' has already lived an earlier life - do not withstand ethical analysis.

"It is hard to identify a moral or human right why a healthy cloned child should be different from a healthy normal child," said Dan Brock, a bioethicist at the US National Institutes of Health in Bethesda. "Even the concept of the right to a unique identity is not disturbed because people develop according to their circumstances, not their genes."

Ortwin Renn, a philosopher at the Academy of Technological Assessment in Stuttgart, added that in the absence of safety concerns, controversy would centre on the time after conception that the embryo is recognized either morally or constitutionally as having equal rights with a person.

Catholics, for example, see this as occurring at the moment of conception, whereas eastern philosophies assign rights at the moment of birth. Even within a culture, it is difficult to get consensus. This, suggests Renn, is why Germany tries to defer this "fundamentally irresolvable" decision to a higher authority such as the United Nations.

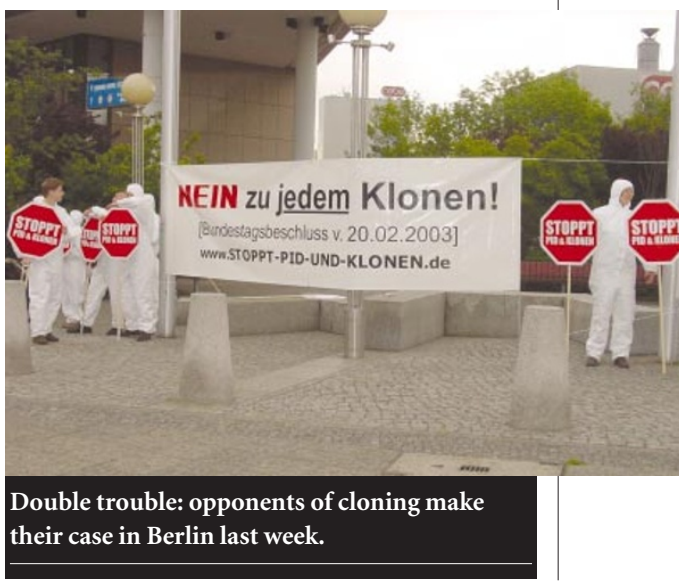

